\title{
Pituca/Mozart Régis nas páginas da Revista do Rádio ${ }^{1}$
}

\author{
Pituca/Mozart Régis in the pages of Revista do Rádio \\ Márcia Ramos de Oliveira ${ }^{2}$ \\ marciaramos@cpovo.net
}

Resumo

Estudo de caso, proporcionando a apresentação de matérias da Revista do Rádio, a partir do acervo da Hemeroteca Digital Brasileira da Biblioteca Nacional em contraposição as matérias e imagens selecionadas por Mozart Regis como demonstrativo da sua trajetória pessoal e profissional. Tem por objetivo observar a construção do artista Mozart Regis sob o aspecto público, mediatizado através da Revista do Rádio e sob sua própria perspectiva por meio da organização de um acervo pessoal/ profissional a partir do portfólio doado a Casa da Memória de Florianópolis/SC.

Palavras-chave: Pituca, Mozart Regis, Revista do Rádio, Portfólio, Hemeroteca Digital Brasileira

\begin{abstract}
Case study, providing the presentation of reports the Revista do Rádio, from the Brazilian Digital Newspaper Library of the National Library collection in contrast the subjects and images selected by Mozart Regis/Pituca as demonstrative of his personal and professional life. Aims to observe the construction of the artist Mozart Regis under the public aspect mediated by Revista do Rádio and under their own perspective through the organization of a personal / professional assets from the portfolio donated to Casa da Memória of Florianópolis/SC.
\end{abstract}

Keywords: Pituca, Mozart Regis, Revista do Rádio, Portfolio, Brazilian Digital Newspaper Library

1 Este texto é resultado do desenvolvimento do Projeto de Pesquisa "Pituca nas páginas da Revista do Rádio: A trajetória do multiartista catarinense Mozart Régis (1948-1970)", desenvolvido individualmente pela Coordenação, sem bolsa de Iniciação Científica, entre os meses de dezembro de 2013 a julho de 2014, vinculado a UDESC. Foi parcialmente apresentado em formato de comunicação, sob o mesmo título, no Simpósio Temático 6 - História oral e memória das artes, da cultura e da criatividade no XII Encontro Nacional de História Oral / ABHO, em 2014.

2 Márcia Ramos de Oliveira é professora no Departamento de História da Universidade do Estado de Santa Catarina (Udesc). 


\section{Um pouco sobre Pituca/Mozart Régis}

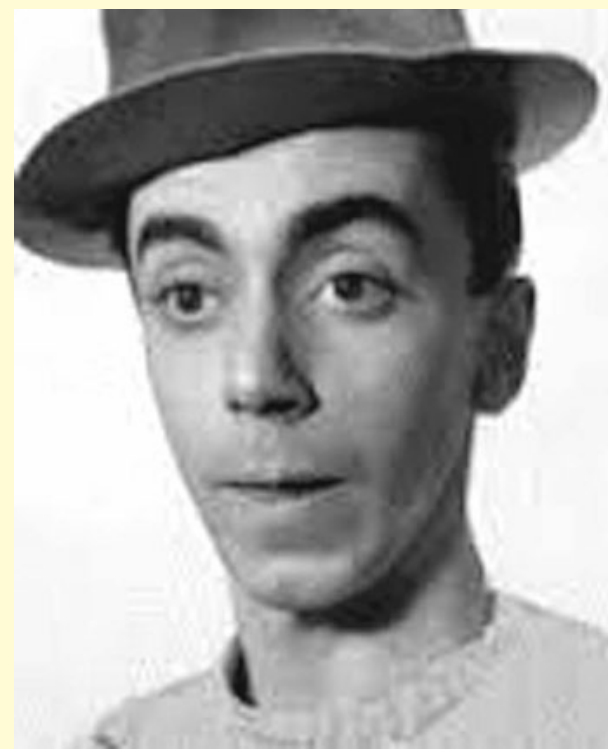

Acervo da Casa da Memória / Portfólio de Pituca

O personagem Pituca praticamente se confunde com sua iniciação artística e trajetória, inicialmente identificado como um tipo infantil, calças curtas e boné, baixinho e frágil, que se alternava entre o público infantil e adulto, na medida em que passou também a ser incorporado como parte da representação peculiar, a exemplo de sua atuação no cinema, onde geralmente está associado ao marido submisso à esposa.

Quase concomitante sua aparição no palco do teatro é também sua estreia no auditório da rádio (Guarujá), quando o mesmo personagem passou a interagir com a linguagem radiofônica, e que neste momento poderia ser pensada como extensão uma da outra. Reconhecido em cena, pelos espaços de contato de público nos auditórios ou no teatro, chegou aos ouvidos também daqueles que não adentraram estes espaços, pela transmissão e sinal aos receptores, enquanto público ouvinte.

A chegada ao cinema, também atravessada pelo teatro, vem de seu contato com a Companhia de Procópio Ferreira, que passava por Florianópolis em turnê no ano de 1946, levando consigo o artista estreante. No Rio de Janeiro como integrante da mesma Companhia, atuou em diversas peças, além do trabalho para além do palco. A experiência e projeção na atividade teatral levou o artista a participar também do cinema através da Companhia Atlântida, onde atuou em quatro filmes conhecidos ("Garotas e Samba", "Aí vem alegria", "E o espetáculo continua", "Assim era Atlântida"), além de outras produções sob a direção de Watson Macedo, em três filmes ("O petróleo é nosso", "Rio, verão e amor") e, entre muitas outras produções em cena e nos bastidores.
Mozart Régis tornou-se um segundo nome para o artista que veio a ser conhecido pelo personagem Pituca, que acabou por confundir-se com a sua pessoa, o sujeito assim constituído. Nasceu em Florianópolis em 1926, onde também começou sua atividade no teatro e na radiodifusão.

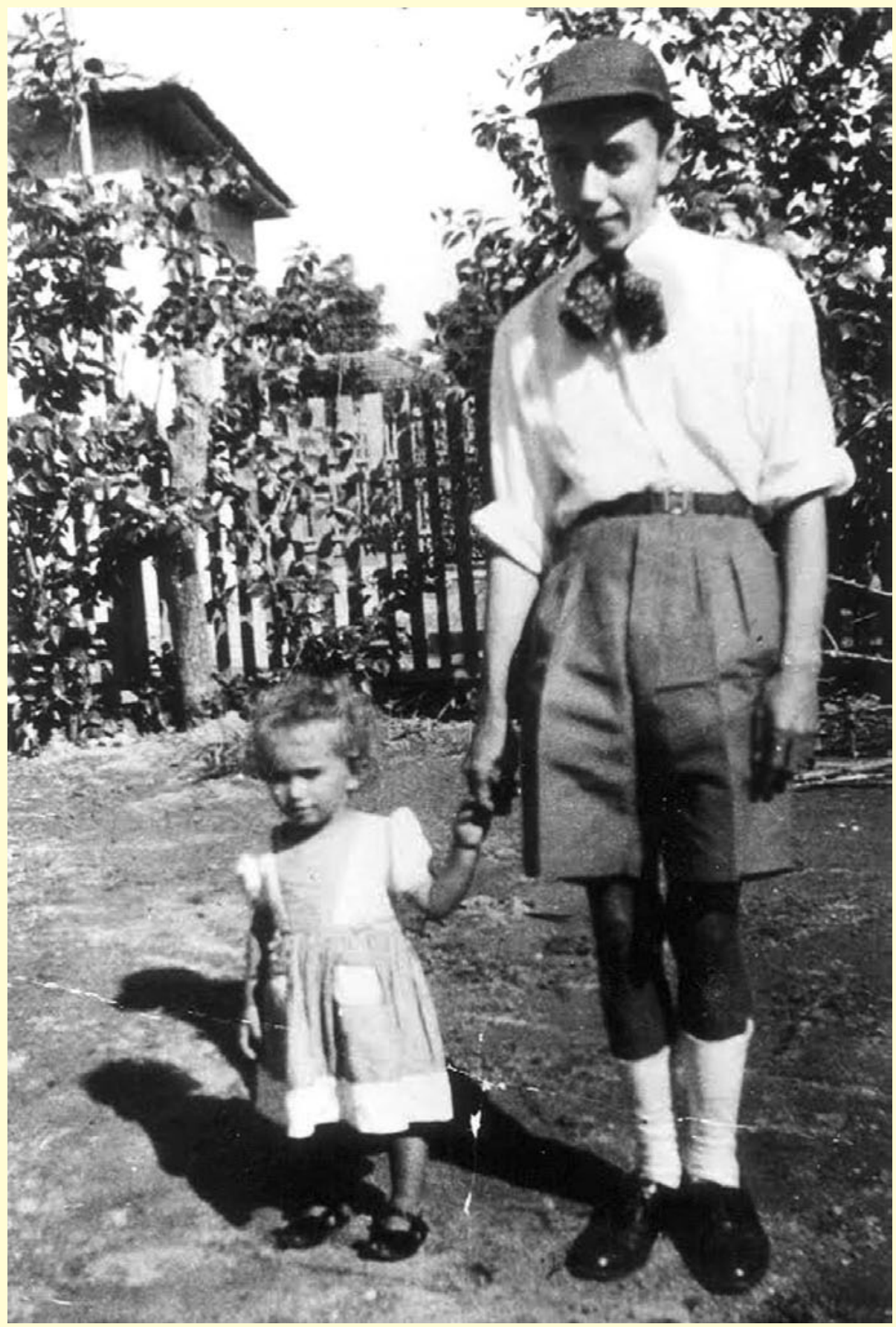

Acervo da Casa da Memória / Port fólio de Pituca 
Diante de sua intensa atividade profissional, inicialmente em São Paulo e depois no Rio de Janeiro, acabou definindo residência nesta cidade, onde se casou e constituiu família. No entanto, continuamente voltava a Florianópolis, em turnês de teatro, divulgando o cinema, e atuando profissionalmente na radiodifusão. Sua inserção e pertencimento a capital catarinense, renderam-lhe diversas homenagens, que se estenderam até o final de sua vida em 23 de julho de 1995, no Rio de Janeiro.

A baixa estatura, o ar de graça, a irreverência e a associação a comicidade e o fato de que contrariando as primeiras expectativas, Pituca chegasse as telas de cinema são os prováveis motivos para que tenha sido identificado em matérias jornalísticas como o "Chaplin brasileiro". ${ }^{3}$ Porém, diferenciando-se de Charles Chaplin, Pituca no cinema seria sempre um ator coadjuvante, servindo de apoio, de "escada" as atuações principais, inserindo o humor como parte da narrativa fílmica, integrando o roteiro como uma expressão paralela, complementar ao centro do discurso.

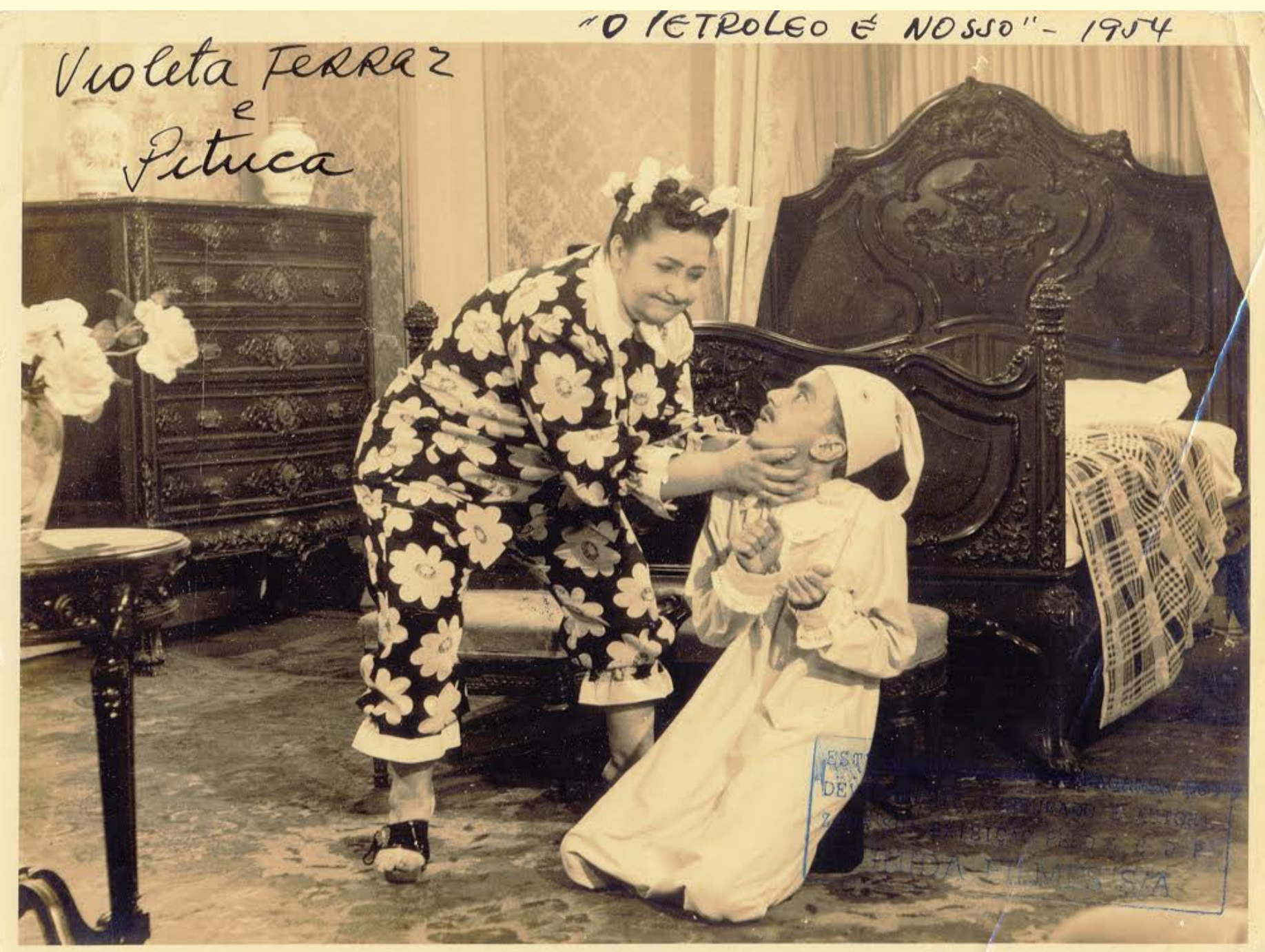

\section{Acervo da Casa da Memória / Portfólio de Pituca}

Sua chegada à televisão coincide novamente com a construção de personagens cômicos, em programas de humor como uma variação do que já havia experimentado no rádio, a partir de esquetes específicos em meio ao conjunto de quadros em sequência. Sua vasta experiência na cena de teatro, cinema, televisão e rádio ampliou-se para além das telas e palcos quando passou a escrever roteiros e novos quadros de atuação, entre outras atividades de apoio as realizações artísticas.

Todo este conjunto de referências relacionadas diretamente ao modelo de construção do personagem e forma de atuação cômica vinculada ao seu tipo físico, leva a pensar na condição de star system (MORIN, 1957) ou ainda de persona assumida pelo artista, como definidor de sua atividade profissional, confundindo-

3 “No cinema, Pituca atuava quase sempre como o marido dominado pela mulher. Já no teatro, foi chamado de 'Chaplin Brasileiro' por sua semelhança física com o comediante.” In: Site Dramaturgia in memorian; acesso: http://dramaturgiainmemorian.com.br/pituca/ 


\section{Artigos}

-se a personagem e o artista. As noções de persona aplicadas de maneira associada, mas não idêntica, podem ser percebidas diretamente ao drama e por isso o vínculo dos estudos nas áreas de psicanálise, teatro e cinema, quando da reflexão sobre o conceito. No caso de Mozart Régis, sua atuação como Pituca também pode ser percebida na acepção destes conceitos na medida em que existe de parte da audiência uma relação de identidade estabelecida com o personagem cômico, que se confunde com a figura do ator, com sua estrutura física ou sua trajetória enquanto humorista. Entre uma representação e outra, diversos elementos constituintes em sua performance formam ao mesmo tempo um e múltiplos personagens, mas partindo sempre da caracterização inicial, enquanto um tipo pequeno, engraçado, ágil.

Segundo Margarida Maria Adamatti,

\section{“(...) O processo tem relação com a configuração do melodrama e com os filmes de estrela.}

A personificação do olimpiano é importante ao melodrama. Este trabalho com a recognição da identidade, mas de forma planificada, diferente da tragédia. (...) A atrizé encarregada de trazer um universo moral a ser questionado ou sedimentado. Por este motivo o entrelaçamento entre intérprete e personagem é desejado, porque a personalidade do papel interpretado é transferida ao artista. (...) Passa a ser o idolo, o responsável também por mostrar valores novos ou sob ameaça, contidos nos filmes. Portanto, a definição da identidade passa da vida ficcional da personagem para a persona da estrela. " (ADAMATTI, 2008 p. 89)

Ainda que a autora desenvolva sua perspectiva de análise voltada às atrizes no cinema, evoca uma dimensão de identificação que também pode ser percebida na figura de Pituca, no jogo estabelecido de reconhecimento pelo público, inclusive pela referência a sua trajetória na Revista do Rádio, na medida em que destaca aspectos presentes da narrativa ficcional em que atua e sua experiência construindo com o público um jogo de inferências. A justaposição dos elementos que caracterizaram sua imagem e expressão tornaram indissociáveis o artista e o personagem, partir da performance construída. Neste sentido, concordando com as considerações sobre o ato performático apresentadas por Ruth Finnegan, ainda que se refira ao uso do canto pela palavra explicitando no valor da enunciação pela linguagem e oralidade a apresentação da narrativa,

“(...) As tecnologias da escrita e da imprensa endossam a substancialidade e durabilidade das palavras escritas. São os textos verbais que aparentemente contêm 'a coisa de verdade'. (...) E há também as tecnologias de comunicação, em transformação permanente. O modelo da escrita como realidade central não desapareceu, mais foi suplantado por canais mais multimodais. O rádio, com seu notável potencial para capturar e transmitir a voz. em performance, já moldou a percepção de gerações, conferindo solidez, aos sons da música vocal com ou sem acompanhamento musical. "(FINNEGAN, 2008, P. 19 e 23)

Junto a isso, outra noção vem a somar-se, quanto a considerar a diversidade de competências profissionais observadas, apontando para sua identificação como multiartista, tendo em vista as várias linguagens e técnicas de expressão percorridas no conjunto de sua trajetória profissional, enquanto tipo cômico no teatro, a correspondência desta atuação nos programas de rádio, a atuação no cinema como personagem secundário, também humorístico, a realização de filmes e em sua divulgação e envolvimento com a promoção desta atividade, a atuação na televisão, voltando à interpretação cômica e à redação de roteiros e esquetes em diversos programas de humor de reconhecida audiência em diferentes emissoras.

Neste sentido, observar a trajetória de Mozart Régis/Pituca implica integrar a construção biográfica a este conjunto de noções que levam a interrogar sobre sua condição de sujeito e personagem, levando a questionamentos quanto até onde aproximam ou integram nesta forma de associação, identificação e caracterização.

Considerando as reflexões sobre biografia na área de história, vale lembrar a contribuição de Benito Schmitt quanto à falta de homogeneidade dos trabalhos desenvolvidos recentemente, díspares em sua concepção sobre o que determina atualmente o gênero. Lembrando, inclusive que boa parte das produções publicadas mais recentemente vem da participação dos jornalistas nesta área. (SCHMITT, 2012).

De sua reflexão, é importante salientar a referência direta ao texto de Pierre Bourdieu, "A ilusão biográfica", fundante quanto à crítica desenvolvida nesta reflexão, apontando para a impossibilidade da construção da biografia como narrativa, na medida em que tal verve implicaria o desenvolvimento de uma intencionalidade de parte do biografado com relação a sua própria trajetória, o que segundo tal perspectiva, não se aplica devido à impossibilidade histórica. (BOURDIEU, 1986) 
$\mathrm{Na}$ reflexão sobre esta condição de artista/sujeito, este trabalho vem explorar como fonte documental algumas das matérias da Revista do Rádio, em formato de magazine, que circulou no Brasil entre os anos de 1948 a 1970; junto ao levantamento documental organizado por Pituca, em formato de portfólio, como um conjunto de materiais indiciários de sua atuação profissional, reunidos pelo próprio artista, resultante de pesquisa realizada anteriormente, localizado na Casa da Memória em Florianópolis. ${ }^{4}$

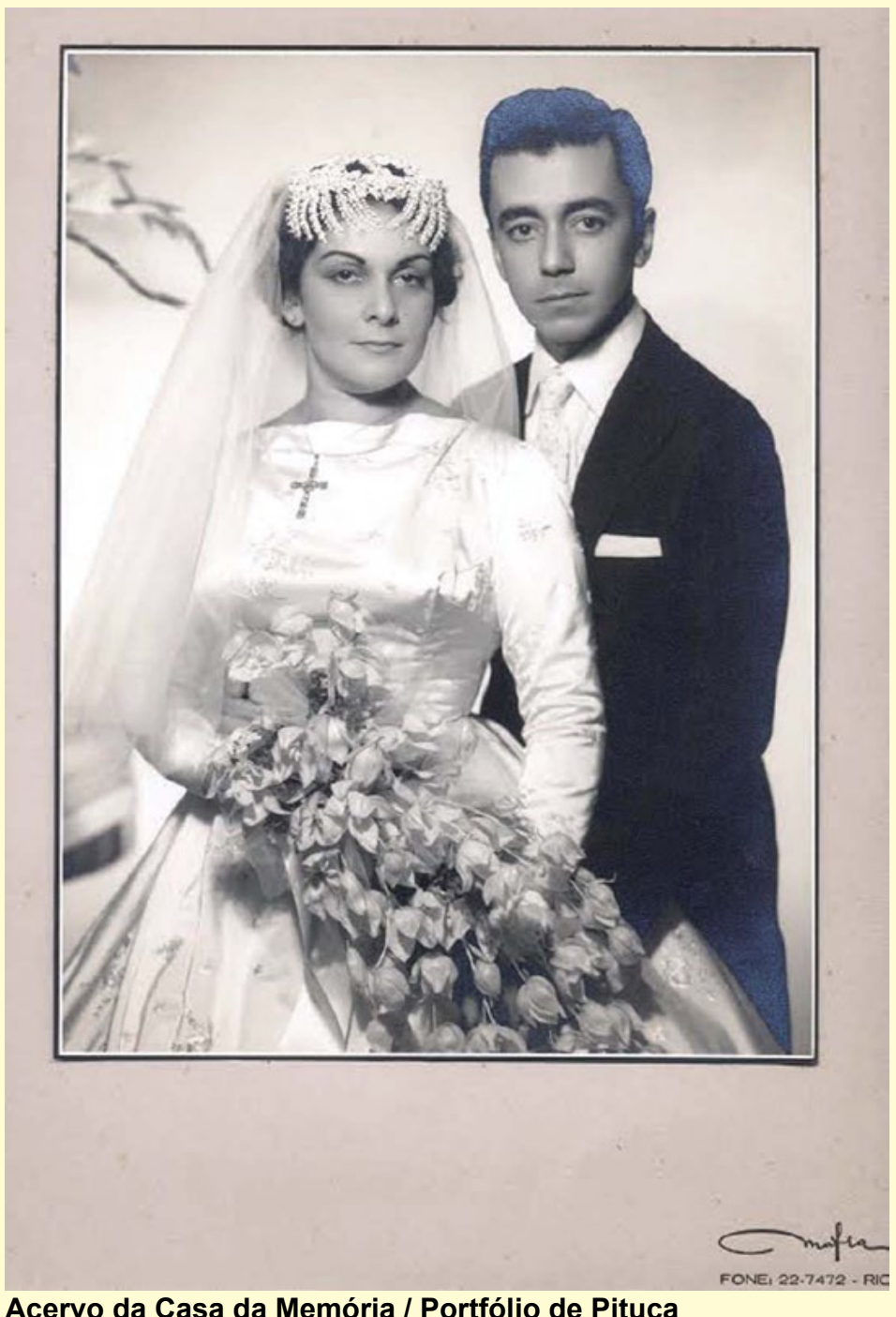

Acervo da Casa da Memória / Portfólio de Pituca
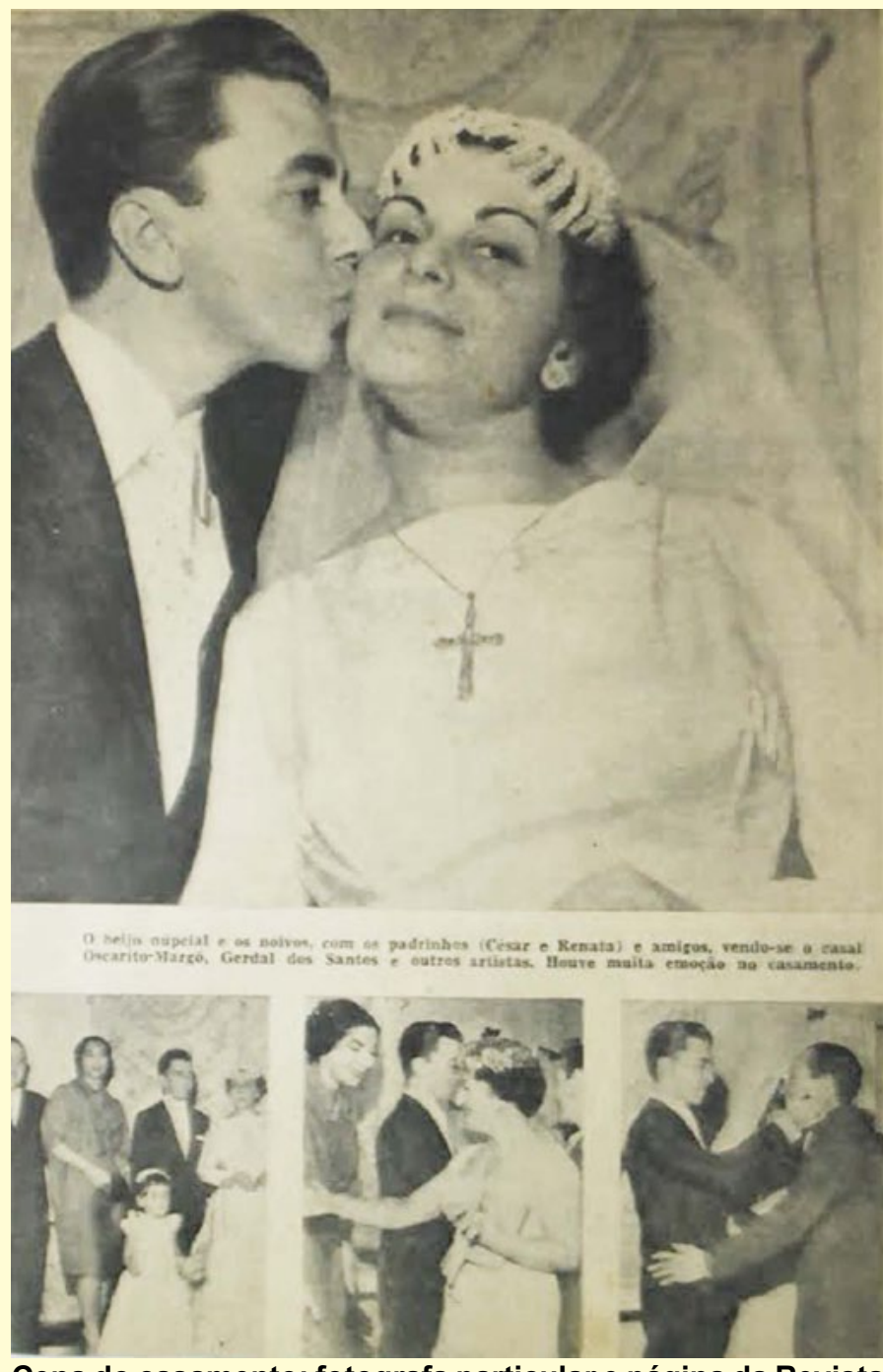

Cena do casamento: fotografa particular e página da Revista do Rádio

\section{Algumas considerações sobre a Revista do Rádio}

Poucos trabalhos foram feitos sobre a Revista do Rádio, considerando a importância deste veículo de comunicação diante da popularidade e sucesso de público que atingiu, especialmente se considerado o período em que circulou, no momento de maior efervescência da radiodifusão no Brasil, tendo a Rádio Nacional como parâmetro de modelo de sucesso no país. Sobre isso, declara Rodrigo Faour,

"Em dezembro de 1949, a Revista do Rádio já vendia 50 mil exemplares, um número muito expressivo para a época, perdendo apenas para O Cruzeiro, revista de variedades que equivalia à Veja de hoje. Esse boom nas vendas motivou a diretoria a torná-la semanal, o que viria a ocorrer a partir de março de 1950. Nesse mo-

4 Sobre o portifólio de Pituca, ressalto minha comunicação e texto de apresentação no XI Encontro Nacional de História Oral (ABHO), realizado na UFRJ, em julho de 2012, intitulado "Portifólio do artista: o que dizem as fotografias de Pituca", como parte dos anais ; acesso: http://www.encontro2012.historiaoral.org.br/site/anaiscomplementares.

Este texto foi resultado do contato com a documentação sobre o artista relacionada como parte do Projeto de Pesquisa "Cenas e cenários: leituras, músicas e imagens de aproximação entre as manifestações de teatro, radiodifusão e cinema (1920-50)”, com apoio da UDESC, sob minha coordenação e que teve a participação das Bolsistas Mariana Rotili da Silveira (entre 2009 e 2010), Tainah Lounge (entre 2010 e 2011), Carolina Rovaris e Cecília Reibnitz (entre 2011 e 2012) e Sheila Gouveia (em 2012). O levantamento documental apresentado como parte do acervo material sobre Pituca foi resultado desta pesquisa. 


\title{
Artigos
}

mento, a redação se muda para um sobrado na rua de Santana, amplia um pouco suas instalações e deixa de ser tão restrita ao que ocorria nas rádios cariocas, passando a ter uma dimensão nacional (com direito a colunas especiais sobre rádios paulistas, mineiras e a seção "A Rádio nos Estados", ainda que as rádios cariocas dominassem o Brasil nessa época) e caindo definitivamente na boca do povo.” (FAOUR, 2002, p. 29)

\begin{abstract}
A breve citação revela no texto deste autor a proposta de sua pesquisa que resultou no livro "Revista do Rádio: cultura, fuxicos e moral nos anos dourados", como sendo uma tentativa de registro sobre os acontecimentos diretamente relacionados a este periódico, a exemplo do que já fizera em trabalho anterior sobre o cantor Cauby Peixoto, quando quis "resgatar um pouco da história do país dos anos 1950" (FAOUR, 2002, p. 12). Pesquisa despretensiosa do ponto de vista da crítica e do rigor acadêmico, o resultado de seu trabalho aponta para um considerável volume de informações sobre o tema, destacando a periodicidade e longevidade da revista, que circulou entre 1948 a 1970 (totalizando 22 anos!), a extensão e abrangência dos temas a que se dedicou, ao tematizar pelo rádio, evocou a memória da comunicação no Brasil também pelo teatro, cinema e televisão e, especialmente, pelo fazer artístico neste período, em matérias, entrevistas e depoimentos do cast das emissoras. Vale ressaltar, ainda, o detalhamento quanto às diferentes seções ou colunas que a revista desenvolveu, com destaque a intitulada "Mexericos da Candinha", ou "A pergunta da Semana”, que equivalem nos dias atuais a aparência de interatividade e reciprocidade de público almejada pelos diferentes veículos de comunicação, quando pretendem demonstrar que são reveladores da opinião pública. A legitimidade e a importância da Revista podem ser percebidas, passados 30 anos do final de sua circulação, o quanto ainda permanece na memória afetiva de várias gerações, como revela o depoimento de Adelaide $\mathrm{Chiozzo}^{5}$, no mesmo livro,
\end{abstract}

"A Revista do Rádio foi tão importante quanto a Rádio Nacional e os filmes da Atlântida, pois divulgava por todo o Brasil a imagem dos artistas. Era uma época em que a televisão não existia ou pouca gente tinha. Os fãs nos ouviam no rádio epegavam a revista para ver a imagem da gente, da mesma forma que ocorria com os filmes da época. Antes dela só haviam revistas mais sofisticadas como a Vida Doméstica. A Revista do Rádio é um marco no meio artístico, um marco de revista popular brasileira."

Deste relato, é importante também salientar a referência à imagem dos artistas. Mais conhecidos pela vOz no dial, ou quando em registro audiovisual no cinema, que atingia um número consideravelmente menor de atuações, tornava possível ao público conhecer a figura do cantor ou cantora, preenchendo o que seria uma lacuna entre o que ouvia e imaginava a partir das locuções, alimentando e construindo as representações e imagens que circularam no período áureo da radiodifusão, especialmente associada ao sucesso do projeto que originou a Rádio Nacional como proposta de hegemonia ideológica e política no Estado Novo. À medida que estas fotografias davam certa materialidade à voz irradiada, novos construtos e representações foram agregados, com destaque ao uso mercadológico na venda de produtos como discos e aparelhos de recepção de áudio, ou ainda mais diversos, de higiene a alimentação e, muito especialmente, a eletrodomésticos, definindo novos padrões de hábitos e comportamentos.

Dóris Hausen e Camila Bacchi (2001), no texto "A Revista do Rádio através de seus editoriais (década de 1950)" apontaram para a intencionalidade de uso da revista, sob a perspectiva acadêmica na comunicação, analisando como o título indica, os editoriais nesta década de 1950, contrapostos aos demais textos que a integram, considerando sua vinculação à indústria cultural brasileira. Também alertam para o fato da ausência de estudos sobre a revista,

"O periodo de 1945 a 1955 do século XX significon o apogeu do rádio na América Latina e em praticamente todo o mundo. Foi a época dos programas de auditório, das radionovelas, dos artistas populares e, também das significativas verbas publicitárias destinadas ao veículo de comunicação de massas mais destacado de então. Naqueles momentos, muitas revistas sobre o rádio foram editadas em todo o continente.

Embora tenham sido consumidas por grande parte da população latino-americana, estas revistas têm sido pouco estudadas em toda a sua amplitude e significado.(...) (BACCHI e HAUSSEN,2001:1)

5 Adelaide Chiozzo foi acordeonista e cantora, fazendo dupla com Eliana Macedo; intérprete da conhecidíssima canção "Beijinho doce"; tendo sido contratada na Rádio Nacional por 14 anos, além de ter participado de 23 filmes nacionais. 


\section{Construindo o personagem, conhecendo o artista}

Para conhecer Pituca / Mozart Régis, alguns cliques de internet não bastam. A pesquisa inicial realizada a partir dos sites de busca local (a exemplo de acervos que podem ser considerados memorialistas, como o Portal Caros Ouvintes, ou o Blog El Bufon, e mesmo nacionais, como a Cinemateca Brasileira e o site Dramaturgia Brasileira in Memorian, fornecem informações iniciais, apontam para o reconhecimento de sua figura e trajetória, porém pouco subsidiam a inserção de suas ações no contexto em que ocorreram.

A observação de outro tipo de material, complementar, mas que subsidiou um conhecimento mais apurado sobre sua atuação em distintos momentos, foi possível através da documentação material obtida na Casa da Memória, mediante doação de acervo feita a esta instituição. O conjunto de documentos doados, entre papéis, fotografias e objetos, denominei em texto anterior de "portfólio" do artista. ${ }^{6} \mathrm{O}$ registro e descrição deste material foi realizada através de pesquisa anterior, do que resultou a disponibilização de um breve catálogo a partir de fotografias e referências a sua identificação. ${ }^{7}$ Esta documentação foi entregue reunida dentro de uma pasta de couro, em formato de álbum, fixada nas diversas páginas, e ainda, ficando "de fora" deste suporte, outros objetos, do que destaco, especialmente, o boné, a casaca (fraque) e os óculos, além de cartazes de filmes e espetáculos teatrais de maior volume.

Em meio à documentação desta pasta, foi identificado um extenso currículo, datilografado e, ao que tudo indica, elaborado pelo próprio Mozart Régis para fins profissionais. Boa parte da orientação cronológica dos dados que orientam a pesquisa sobre sua trajetória tem se apoiado nesta referência.

O cuidado em apresentar as diversas atividades exercidas, assim como outras referências indiciárias destas atuações, demonstra a preocupação do artista Pituca em detalhar sua trajetória e também demonstrar o reconhecimento ao que veio realizando, através de notícias pontuais, que permitiram visibilidade e legitimidade a partir de narrativas midiáticas. Cabe salientar a natureza e especificidade destes documentos, a citar:

1. Atividades Profissionais: Currículo extenso, detalhado, sobre sua atividade profissional (ao que tudo indica, elaborado por ele); com outros currículos breves, menos volumosos; Crachás de Pituca na Rádio Nacional com outros documentos timbrados alusivos a sua atuação profissional na Emissora; Carteiras sindicais e profissionais diversas; Boletins informativos e editoriais das diferentes emissoras de rádio e televisão em que participou (Rede Globo, Tv Rio, Rádio Nacional, e outras) ; Boletins informativos e catálogos de cinema (Cine Fan e outros ); Diplomas e certificados de atuação em cena; Esquetes / scripts de programas de humor elaborados por Pituca; roteiros de programação e relação do elenco;

2. Divulgação da atuação artística e profissional nas diferentes áreas: Programas dos espetáculos produzidos por Pituca ou em que atuava em cena; Recortes de jornais e revistas contendo a divulgação dos espetáculos teatrais e filmes a partir da atuação de Pituca; com recortes de jornais e revistas diversos, por diferentes temas, incluindo sua trajetória específica; Programação da temporada de julho de 1946 do teatro Sete de Abril, de Procópio Ferreira e sua companhia de comédias. Pituca consta no elenco de algumas peças: "Minha Mulher É Ciumenta", "Quebranto" e "Por causa do Lulú"; Diversos cartazes de divulgação de filmes em que participou; Libreto produzido pela LIESGA (Liga das Escolas de Samba do Grupo de Acesso, no RJ), alusivo ao carnaval e 1995, que teve por tema a Companhia Atlântida de Cinema; Diversos bilhetes, cartões e fotografias alusivos a Pituca, por diferentes personalidades do meio artístico.

3) Outras atividades profissionais e artísticas além das conhecidas: Letra de música, de autoria indefinida; Crachá de participação no do VII Festival Internacional da Canção Popular. Produção. 4-017. No verso: coordenador de bastidores; Diversos informes publicitários, de temas variados (talvez indicando a participação de Pituca em sua formulação); cartaz do resultado das eleições: "Super Cobertura Nacional", na qual Mozart Régis aparece como correspondente estadual da rede Rádio-jornalística do país, não identificado o ano.

4) Reconhecimento profissional, artístico e pessoal (homenagens): Convites, participações e homena-

6 Texto já referenciado na nota 3. Ainda sobre esta pesquisa, destaco o quadro anexo ao final do artigo, que contempla em parte o levantamento documental realizado.

7 Este material foi disponibilizado a Casa da Memória, como facilitador no acesso à documentação existente, acondicionada dentro de envelopes. Identifica o conteúdo de cada envelope, a partir do registro fotográfico e sua descrição. 


\section{Artigos}

gens apresentados a Pituca; recortes de jornais e revistas com mesmo tema; Conjunto de diversas charges e caricaturas tendo Pituca como motivo; Cópia do documento de outorga da medalha do mérito Anita Garibaldi, pelo Estado de Santa Catarina (25 de novembro de 1986) ; Crônica envolvendo sua atuação na Rádio Guarujá, em Florianópolis; Convite para entrega do troféu Manezinho da Ilha, dia 24 de agosto de 1990, no Clube Barriga Verde dos Oficiais da Polícia Militar Canasvieiras/ Florianópolis; junto, cópia de discurso de agradecimento proferido por Pituca; Bilhetes manuscritos de políticos e personalidades locais em agradecimento; Recortes de jornais locais informando sobre o acervo de Pituca entregue a Casa da Memória / Florianópolis; Recortes de jornais locais em matérias sobre Pituca, após sua morte.

5) Documentos pessoais e objetos: Título de eleitor (1945); Fotografia do casamento e do filho; Páginas de um periódico (não identificado) com fotos do casamento de Pituca, com a reportagem intitulada "Pituca virou "Homem Sério". Fotos de Geraldo Azevedo, em 4 páginas (não é a mesma matéria da Revista do Rádio, ainda que o tema se repita). Fotorreportagem, contendo as páginas da Revista do Rádio sobre o casamento. E, ainda, peças do vestuário e de uso: óculos, boné e casaca.
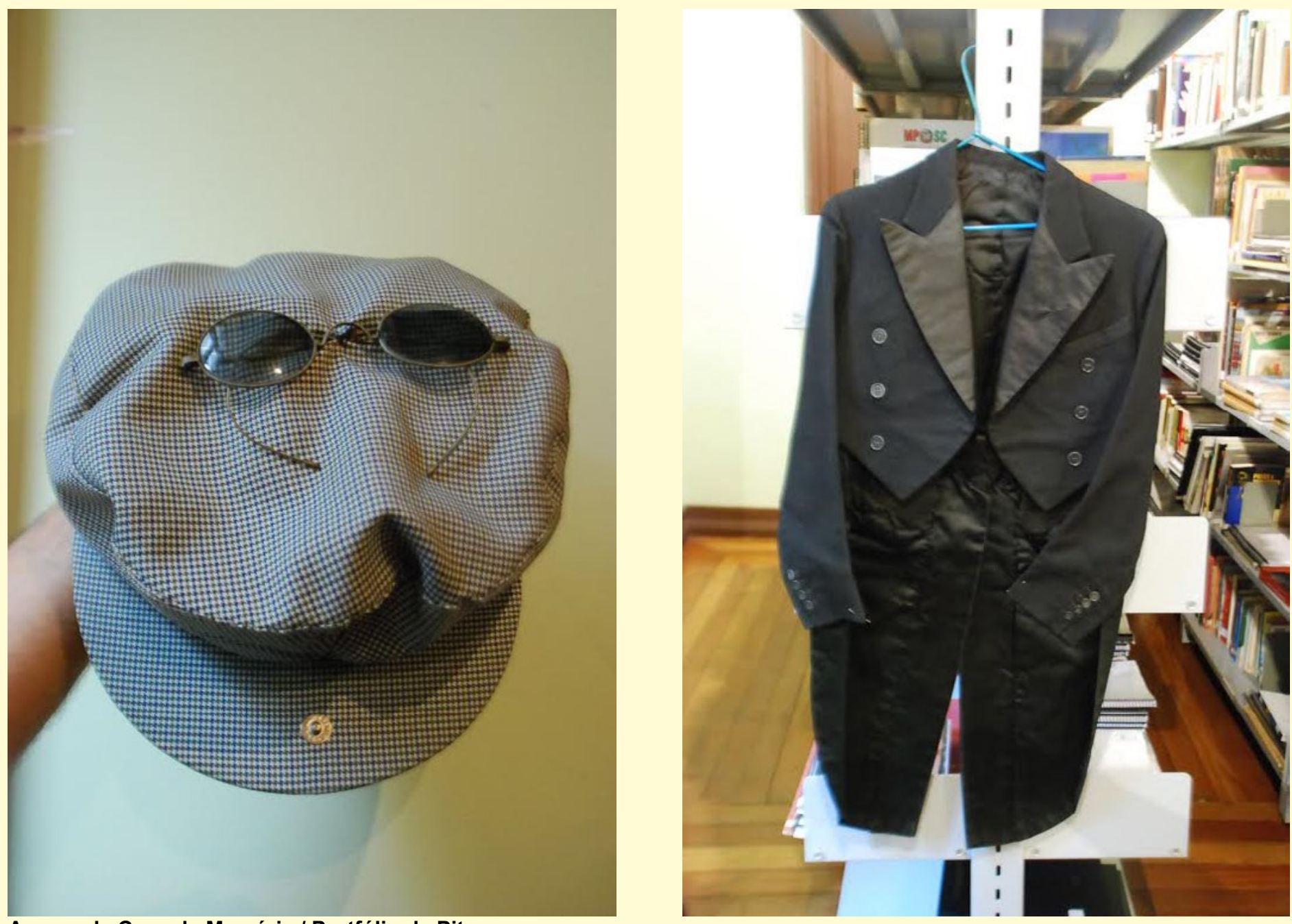

\section{Acervo da Casa da Memória / Portfólio de Pituca}

O desenvolvimento deste texto, tendo por aproximação a Revista do Rádio, relaciona-se diretamente a esta perspectiva de observação, pois procura perceber a inserção deste artista na atividade cultural brasileira, na medida em que se tornou alvo de interesse daquele periódico, tendo em vista sua produção no centro do país e circulação pelo território nacional.

A pesquisa desenvolvida sobre as referências que mencionam a presença de Pituca na Revista do Rádio ocorreu fundamentalmente utilizando-se a busca através da Hemeroteca Digital Brasileira, pela Biblioteca Nacional, ainda que alguns números da mesma Revista tenham sido observados em formato impresso.

No levantamento realizado, foram obtidas 41 ocorrências, sendo comprovadas como de atuação de Pituca/Mozart Régis apenas 36. Sua trajetória é mencionada na Revista entre os anos de 1953 a 1964, havendo um silenciamento sobre ele após esta data. Na maioria, são notas breves, em colunas específicas, desta- 
cando separadamente sua presença inicialmente no teatro (revista), a projeção e, em decorrência, o convite para o cinema, a contratação pela Rádio Nacional como comediante destacado, a continuidade da atividade teatral, o ingresso na TV-Rio. Todas estas atividades são desenvolvidas de forma concomitante, além do fato de referir também a participação de Pituca na Rádio Guarujá, em Florianópolis, já reconhecido do grande público pela Rádio Nacional. Ainda, sua participação em uma rádio mineira (Rádio Barbacena), quando do interregno entre a renovação de seu contrato com a Rádio Nacional. Importante também cita sua contínua presença no lançamento dos filmes em que esteve em cena e/ou na produção e bastidores.

Todas estas referências reforçam a ideia da multiplicidade de sua performance e maneira de atuar, assim como comprovam que a experiência artística no período, entre as décadas de 1940 a 1960, comportava tal diversificação como perfil profissional aproximando e interligando as linguagens sonoras e audiovisuais, além da importante presença em cena direta, como na participação dos palcos de teatro e auditórios de rádio. Detalhando melhor, especialmente tendo como perspectiva a abordagem feita pela Revista do Rádio, a maior incidência de ações teria ocorrido no ano de 1957, totalizando 11 referências, sendo que neste ano, Pituca atuou simultaneamente em todas estes espaços, a citar, na Rádio Nacional (comediante), no Teatrinho Jardel (Rio de Janeiro), no filme lançado no carnaval pela Companhia Atlântida intitulado "Garotas e Samba" (comédia sob a direção de Carlos Manga), na Tv-Rio em um quadro humorístico intitulado "O caboclo aponta o sucesso", onde interpretava um boneco inquirido pelo "ventríloquo" Tônio Luna. Ainda em 1957, consta sua vinculação a ABR, então sigla da Associação Brasileira de Radiodifusão, equivalente à associação sindical corporativa dos profissionais da área naquele momento. Chama a atenção sua estreita vinculação ao casal Renata Fronzi e Cesar Ladeira, muito conhecidos no período, sendo a primeira uma estrela no teatro de revista, no cinema e posteriormente na televisão e o segundo, um experiente produtor da Rádio Nacional e Tv-Rio, a partir de sua profícua e contínua produção de comédia e peças musicadas no Rio de Janeiro e em São Paulo. Aparentemente uma relação de amizade e profissionalismo, pois Pituca entrou em cena várias vezes com Renata Fronzi no teatro e cinema e esteve vinculado às instituições e iniciativas dirigidas por Cesar Ladeira. Esta aproximação também é documentada pela Revista do Rádio em âmbito particular, familiar, quando da sua presença no casamento de Pituca, em 1959, e no nascimento do primeiro filho, em 1961.

Apesar da intensa atividade profissional de Pituca, as matérias mais destacadas sobre ele na Revista do Rádio são mesmo o casamento e nascimento do primogênito, apresentadas como fotorreportagem, o que indica o prestígio deste artista. Não foi capa da revista nenhuma vez. As demais referências encontradas em notas breves, em meio as colunas da Revista do Rádio associadas a outros trabalhos destacados, porém, podem ser consideradas tão importantes quanto a matéria de destaque, pois apresentam a pluralidade deste grande artista e o amplo espectro de sua atuação, em curto espaço de tempo.

Quando observamos a trajetória que destaca em seu portfólio, especialmente nas datas elencadas em seu currículo profissional, percebe-se como já vinha realizando muitas atividades antes do reconhecimento pela Revista do Rádio, que só registrou sua participação a partir de 1953, quando a revista “Ok Baby”, da Companhia Zilco Ribeiro, batia recordes de bilheteria no Teatro Follies, no Rio de Janeiro.

No ano seguinte, em 1954, sua participação no cinema já é notada, tendo sido lançado o filme "Carnaval em Marte" já no início de 1956. Os filmes musicais (ou musicados, como uma extensão do teatro de revista !), continuam, e ainda assim, em 1955 Pituca retorna a Florianópolis atuando na Rádio Guarujá com o consagrado programa "Pitucadas", marcando sua presença no público infantil. Neste mesmo ano, foi contratado pela Rádio Nacional, com a rádio-atriz catarinense Maria Alice Ribeiro.

Do seu portfólio, constam os indícios também da experiência adquirida antes da chegada ao Rio de Janeiro, tendo iniciado sua atividade profissional na Rádio Guarujá, de Florianópolis, em 1942, e ampliando o espectro de sua atuação ao deixar a cidade em 1948 para acompanhar a Companhia (de teatro) de Procópio Ferreira. Com esta companhia, excursionou inicialmente pelos estados do Sul, seguindo para São Paulo em 1948, e a partir de sua participação em diversas peças, no Rio de Janeiro participou e realizou a sonoplastia de "O Divórcio", onde foi estreante Bibi Ferreira. Retorna a Florianópolis em 1950, dando continuidade à atividade na mesma Rádio Guarujá. Nesta emissora, desenvolve os programas "O mundo é uma bola", no qual pela primeira vez foi apresentada uma orquestra cubana com 40 músicos. Posteriormente, passou a apresentar, como já mencionado, o programa Pitucadas, sendo que no ano de 1951, apresentava uma série de peças 


\section{Artigos}

infantis no Teatro Álvaro de Carvalho, também em Florianópolis. Seu retorno ao Rio de Janeiro aconteceria em 1953, pelo ingresso justamente na Companhia Zilco Ribeiro, no mesmo Teatro Follies, em Copacabana, com a peça "Mulheres... Cheguei”. Em 1954, iniciou sua participação no que chamou "Companhia Cesar Ladeira-Renata Fronzi”, em São Paulo. O primeiro filme, sob a direção de Watson Macedo, “O petróleo é nosso" seria lançado em 26 de julho de 1954, sendo que neste mesmo ano ainda filmaria o também já citado "Carnaval em Marte". Os dados de acervo da Cinemateca Brasileira apontam para sua atuação direta e indireta em pelo menos 22 filmes, considerando seu trabalho atrás das câmeras. ${ }^{8}$

O período em que Pituca desaparece de cena, ao menos em frente das câmeras e /ou palco, pode ser mais bem observado no portfólio do artista, a partir do grande número de homenagens recebidas, em sua idade mais avançada. As caricaturas são uma evidência importante na alteração do próprio personagem, que agora se apresenta portando óculos que pesam na fisionomia, além do boné e roupas mais circunspectas. Como se o personagem original fosse esmaecendo aos poucos, coincidindo com as imagens da fotografia.

Finalizando este texto, ficam muitas perguntas.

De que é feito o artista? A trajetória de Pituca, entre o personagem e o sujeito, em sua multiplicidade de atuações, possibilita refletir a respeito. $O$ fato de assumidamente ter desenvolvido um personagem exacerba a relação que existe entre a tentativa de construção da biografia como intencionalidade e ficção, na medida em que define a impossibilidade em que venha a definir-se como ação histórica essencialmente. Indiretamente, poderia ser considerado o triunfo da ficção sobre a historicidade do sujeito ao revelar tão profundamente o personagem, ao tornar indissociável da personalidade original.

O portfólio como exercício de registro de memória, o currículo profissional como possibilidade de

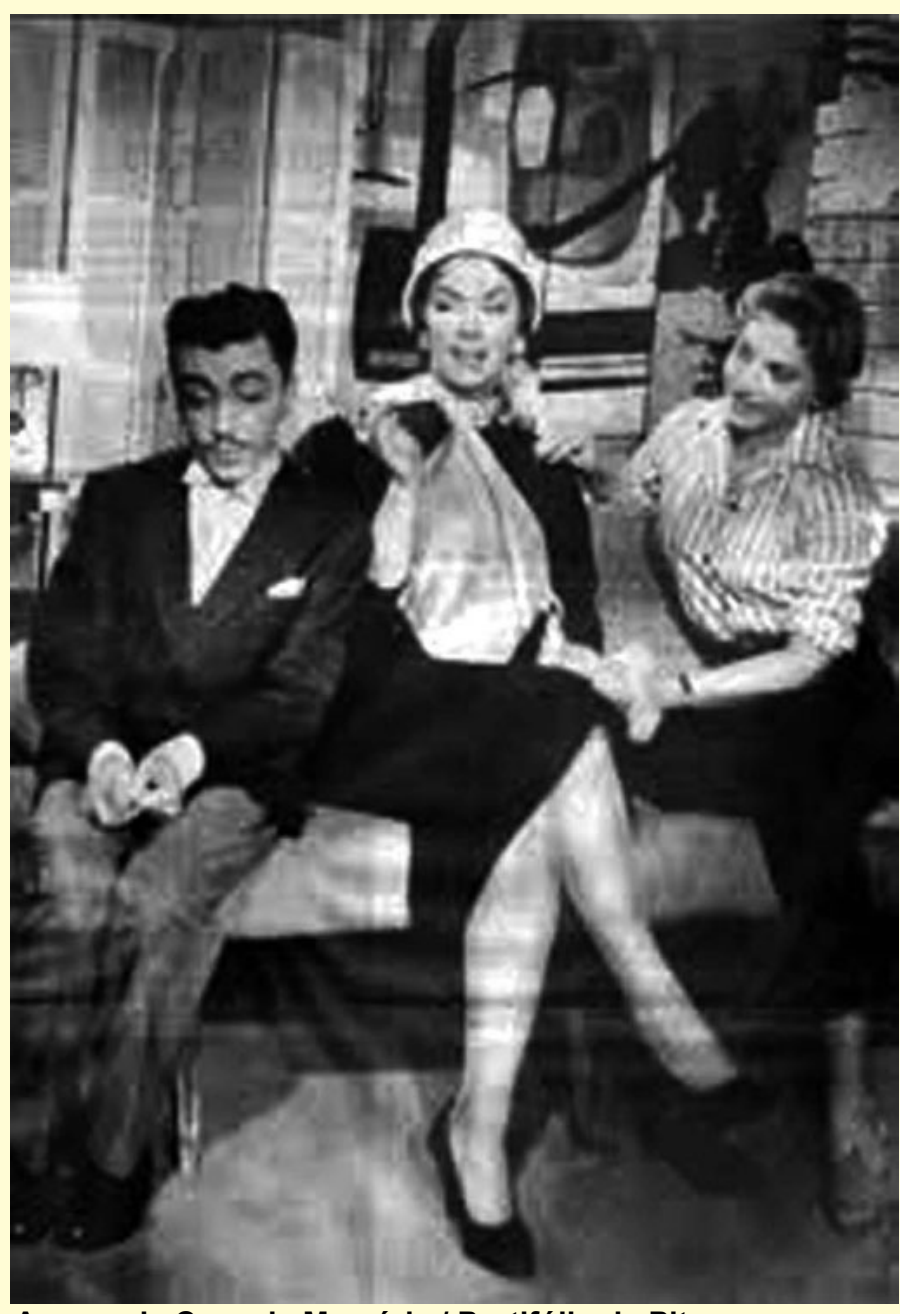

Acervo da Casa da Memória / Portifólio de Pituca encontro com o sujeito, são aspectos ainda a desenvolver como parte do trabalho de evocação e disputa de versões entre o historiador e o biografado. A quem pertence a história e, neste caso, a quem caberia contar/
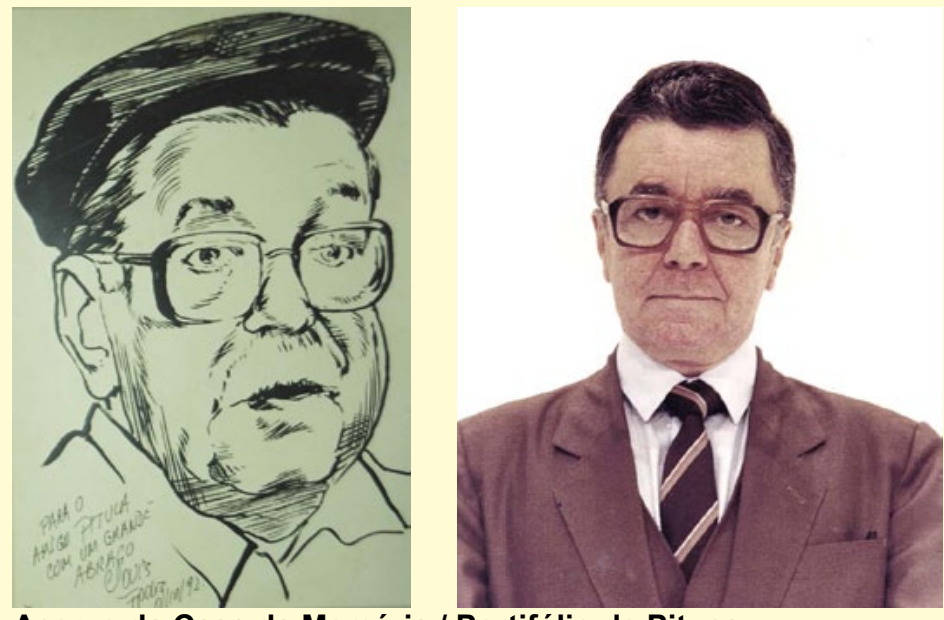

Acervo da Casa da Memória / Portifólio de Pituca

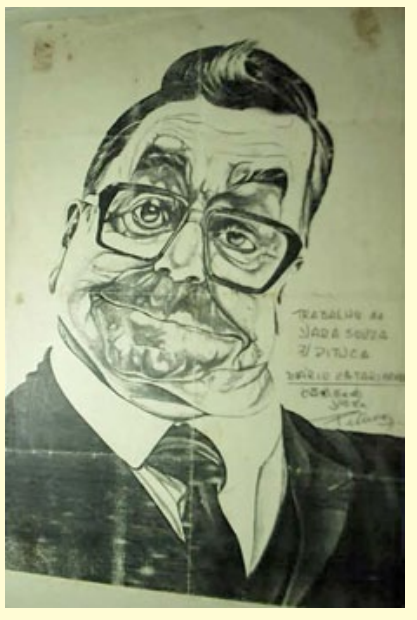

narrar?

Persona ou sujeito histórico? Como não construir esta aproximação ao pensar sobre a rica experiência de vida de Pituca/Mozart Régis sem se sentir tentado a elaborar uma narrativa sobre o contexto em que viveu? Este trabalho é resultado, em parte, desta provocação.

8 Dados da Cinemateca Brasileira; mediante acesso: http://www.cinemateca.gov.br 


\section{Referências bibliográficas:}

ADAMATTI, Margarida Maria. A crítica cinematográfica e o star system nas revistas de fãs: A Cena Muda e Cinelândia (1952-55) . Dissertação de Mestrado / PPG em Ciência da Comunicação / ECA / USP, 2008.

BOURDIEU, Pierre. A Ilusão biográfica. (1986) In: FERREIRA, M.M.; AMADO, J. (Org). Usos e abusos da História Oral. 8ed. Rio de Janeiro: Fundação Getúlio Vargas, 2006.

CALABRE, Lia. A Era do Rádio - Memória e História. Anais do XXII Simpósio Nacional de História, João Pessoa, 2003. Acesso: http://www.anpuh.org/XXII_simposio

FAOUR, Rodrigo. Revista do Rádio: cultura, fuxicos e moral nos anos dourados. Rio de Janeiro: Relume-Dumará: Prefeitura da Cidade do Rio de Janeiro, 2002.

FINNEGAN, Ruth. O que vem primeiro: o texto, a música ou a performance? In: Palavra cantada: ensaios sobre poesia, música e voz. Rio de Janeiro, 7Letras, 2008, p. 15-43.

HAUSSEN, Doris Fagundes e BACCHI, Camila Stefenon. A revista do rádio através de seus editoriais (década de 50). Disponível em: http://www.lume.ufrgs.br/bitstream/handle/10183/435/000309390. pdf ?sequence $=1$, acesso em setembro de 2013.

MORIN, Edgar. As estrelas: mito e sedução no cinema. Rio de Janeiro: José Olympio, 1989.

Cultura de massas no século XX. O espírito do tempo - 1, neurose. Rio de Janeiro: Forense Universitária, 1981.

OLIVEIRA, Márcia R. Portifólio do artista: o que dizem as fotografias de Pituca. In: Anais do XI Encontro Nacional de História Oral (ABHO); acesso: http://www.encontro2012.historiaoral.org.br/site/anaiscomplementares

RIOUX, Jean-Pierre. "Entre história e jornalismo”. IN: CHAVEAU, Agnes; TÉTARD, Philippe. (Orgs.) Questões para a história do tempo presente. Bauru: EDUSC, 1999.

SCHMITT, Benito. História e biografia. (Capítulo 10). In: CARDOSO, Ciro F. e VAINFAS, Ronaldo (Orgs) . Novos Domínios da História. Rio de Janeiro: Elsevier, 2012.

SILVA, Sônia Maria de Meneses. A operação midiográfica: a produção de acontecimentos e conhecimentos históricos através dos meios de comunicação - A Folha de São Paulo e o Golpe de 1964. 2011. Tese (Doutorado em História) - Universidade Federal Fluminense.

\section{Outras referências:}

Blog El Bufon. Acesso: http://manekolopp.blogspot.com.br/

Cinemateca Brasileira. Acesso: http://www.cinemateca.gov.br

Dramaturgia Brasileira in Memorian. Acesso: dramaturgiainmemorian.com.br

Hemeroteca Digital Brasileira / Biblioteca Nacional - Revista do Rádio . Acesso: http://hemerotecadigital. bn.br/artigos/revista-do-r $\%$ C3\%A1dio

Portal Caros Ouvintes. Acesso: http://www.carosouvintes.org.br/ 